\title{
CHANCE ENCOUNTERS BETWEEN BODY AND BUILDINGS: NEW TECHNOLOGIES IN ARCHITECTURE AND DANCE
}

\author{
SAM SPURR \\ Faculty of Design, Architecture and Building \\ University of Technology, Sydney \\ PO Box 123, Broadway, NSW 2007, Australia
}

Samantha.spurr@uts.edu.au

\begin{abstract}
The fields of dance and architecture initially seem in direct opposition - one dedicated to movement and the other to stasis. In many ways dance appears to hold the many qualities ever beyond architecture; the opportunity of flight, of 'liveness', of the ephemeral. Importing ways of thinking as well as doing from dance into architectural practice is conditioned through the shared focus on the encounters between bodies and spaces. In grappling with the impact of new technologies on the design process, new kinds of movement and spaces are being produced.

A key tactic that has emerged within both fields is that of chance. This is arguably the most radical shift that has occurred in the architectural design process. As well as the growing explorations of interactive, multi-media and virtual technologies in dance performances, has been the expansion of notational and choreographic programs that utilize unpredictability. The move toward abstracted systems in these programs endeavours to incorporate energy, force, direction and intent, opening up choreographies to undetermined movements. In this context what dance may provide for architecture, are methods that respond to the difficulty in retaining the animate body in the virtual acrobatics generated by new, generative, architectural programs.

In this paper I will be examining the transformation of the architecture drawing through generative modelling programs based in indeterminacy. The implications of these new methodologies in terms of the design process and the animate body, are viewed in relation to dance experimentation in this area. By specifically looking at the digitised body geometries of choreographer William Forsythe, I hope to open both fields to new encounters between bodies and buildings.
\end{abstract}

\section{Introduction}

The fields of dance and architecture initially seem in direct opposition - one dedicated to movement and the other to stasis. In many ways dance appears to hold the many qualities ever beyond architecture; the opportunity of flight, of 'liveness', of the ephemeral. They share however the key interest in the encounter between bodies and architecture. This encounter in both disciplines has shifted and been reshaped by new technologies in design and production.

While in architecture the move toward abstracted systems in these programs have meant the incorporation of multiple forms of information, choreographers have pursued the incorporation of 
energy, intent and force. Most importantly for both fields has been the strategy of potentiality. Indeterminacy as a creative strategy is beginning to achieve acceptance in architectural practice, a change I argue to be the most radical shift in the architectural design process. In this context what dance may provide are methods that respond to the difficulty in retaining the animate body in the virtual acrobatics generated by new, generative, architectural programs.

This paper examines the transformation of the architecture drawing through generative modelling programs based in indeterminacy. Rather than focusing on the digital programs themselves, it is concerned with the new process of thinking that these programs have instigated. I want to examine how the understanding of the design process has changed. The implications of these new methodologies in terms of the design process and the animate body are viewed in relation to dance experimentation in this area. What better way to describe the relationship between these issues than Brian Massumi's description of this new mode of architecture as 'the art of the architect is the art of the leap' (5). The leap is an act of daring, a performance not only of the stage but of the everyday. It signifies the risk of arbitrariness and the novel outcomes that this risk allows. By specifically looking at the digitised body geometries of choreographer William Forsythe, I hope to propose new incorporations of animate bodies into architecture

\section{Intersections in Dance and Architecture}

In order to escape the presentation of the purely tectonic elements of architecture in the drawing, it is necessary to look to other disciplines. By focusing on bodily movement, dance is a logical starting point for exploring new graphical possibilities for bringing bodies into paperspaces. Movement diagrams as well as dance scores provide alternative notational systems that can be brought into the architecture drawing.

The relationship between dance and architecture has been bound in the dichotomy of performers/audience against stage/theatre architecture, both introverted toward their own specific needs. As both disciplines in the $20^{\text {th }}$ century endeavoured to break away from their historic ties, their aims began to converge. While Classical forms of Western Ballet focused on two-dimensional patterns of the body, contemporary dance has become known for exploring the physicality of the body carving and interacting with space. Modern dance can be read as an attack on the geometry of the Cartesian space, which classical ballet was contrived within. Space is reconsidered as solid and interactive. John Rajchman notes the relationship between dance and architecture as their mutual concern with gravity (52). The desire to understand it, use it and surpass it provides a shared goal. This goal of lightness and floating has been facilitated by new materials, but it is also a strategy imported by digital design programs where buildings virtually float on the screen.

\section{Architecture Drawing Systems}

Unsettled by technological advances, the central architectural issues of drawing, space and the animate body are in flux. For architecture, space has been constructed by the two-dimensional drawing, firmly grounded in the physical. Despite the use of three-dimensional images, they remain dictated by the same systems of hand drawings. The perspective is still that of gods or ghosts, either from up high or as if you were plastered into an interior wall. Rather than the mere replication of traditional forms, Computer Aided Design programs present the opportunity to free architecture from orthogonal geometry, with software from industrial design, aviation, film and auto design, now finding their way into architecture. What was once theoretical musing on alternative geometries and mathematics, are now architectural possibilities. Using algorithms to set up mathematical frameworks in which to generate forms does not demand a computer, as proved by Antonio Gaudi's architecture. What is now different is the accessibility and speed computers lend these complex processes to designers. What this means for the process of making architecture is an entirely new set of tools with entirely new potential outcomes.

The work of architecture in the digital domain subverts the dichotomy that has traditionally been maintained between the virtual and the actual. This distinction enforces an inability to see digital architecture as more than simply an image on a screen. However a new kind of design process is emerging, generated by these new processes of translation. In turn it is informing a new theory of design. New computer design programs have led to an emphasis on process and technique rather than the final image. With it new architecture methodologies are appearing based on organic and self-perpetuating systems. 


\section{Potential Acts}

Amongst the various implications of these new issues for architecture, this paper will on focus on potentiality. Potentiality is also about improvisation, about indeterminacy, about chance. Inherent in these terms is the risk of the unknown. This means giving up control and giving up autonomy. The illusion of complete control is what architects stand to loose with these new programs. Brian Massumi describes these technologies as generating a 'post-heroic' architecture because the traditional role of the architect as creative genius of a finished object is replaced with a less attractive position of 'creative facilitator' (9). The focus is on process and technique rather than finished a form. Rather than the signature work of the architect, the building becomes a collaboration between the designer, data and the technology. In this new process the computer is not an imaging device, but a medium in a process of emergence. They are performative methods, based in the doing process of design rather than a static representation of forms or ideas. It becomes an art of potentiality, creating multiple possibilities rather than coming up with a single, perfect answer.

This mode of working is not limited to architectural design but is indicative of a wider, cultural shift in thinking about objects in the world. In reflecting on this current state, the writing of Giles Deleuze has shown to be particularly applicable. Deleuze describes this reconfiguration of the object, an understanding that can be used to describe this new way of making architecture:

The new status of the object no longer refers to its condition to a spatial mold in other words, to a relation of form-matter but to a temporal modulation that implies as much the beginnings of a continuous variation of matter as a continuous development of form (19).

Deleuze declares that object making can no longer the understood simply in terms of its final product. Instead, the entire process of it's making must be considered, a process that is now based on continuous transformation.

\section{Drawing Chance}

The avant-garde composer and artist John Cage inspired many choreographers and performers during the $60 \mathrm{~s}$ and $70 \mathrm{~s}$ to incorporate potentiality and chance into their work. Cage's performance scores merge mapping techniques and informational systems, pushing the conventional assumptions of authorial control. Similarly, the contemporary dance choreographer Merce Cunningham has been known to choreograph dance sequences by rolling dice. However potentiality in choreography is not only not knowing the next move in a sequence, but what that move could be in space.

Robin Evans describes the difficulty of the architecture drawing is that unlike other kinds of drawings it occurs prior to reality (165), rather than after it like the choreographic score. Both architecture and dance drawings do not aim to represent past actions, but future ones. This means building flexibility into the performance script. Traditional ballet scores and notations present only body shapes, where teaching becomes a process of mimicry. They are formulated on defining fixed events. In contrast, contemporary choreographers have endeavoured to understand that notations must present a body that is never still, but holds multiple potentialities of movement.

In their dismissal of Cartesian space and traditional dance forms, many contemporary choreographers have drawn on different artistic disciplines to present new kinds of movement and interaction. In breaking away from traditional dance typologies, new forms of documentation are needed. New technologies in digital, spatial imaging have become central to creating systems that can document and represent the essentially live medium of dance. The most famous example is Cunningham, who uses dance notation as a creative starting point, drawing on new technologies. Cunningham was the first notable choreographer who began experimenting with integrating computer technologies into dance works during the late 1990s. He uses LifeForms software (now called DanceForms), as a generative device for exploring new kinds of movement. It is ideal for use in collaboration with live performances and as a tool for creating new kinds of movement. In his well-regarded production of BIPED in 1999 with digital artists Paul Kaiser and Shelley Eshkar, motion capture images were projected onto scrims, allowing dances to perform in real time with their avatars.

Accepting the scripting of living bodies in architecture means finding new ways of incorporating these bodies into the design process. Instead of focusing on the documentation of solid forms, to look at bodily transition and spatial transaction is to bring into the drawing process possibilities for chance and improvisation. As contemporary dancers such as Cunningham and 
Forsythe utilize new technologies, the disciplines of dance and architecture start to converge. By focusing on the moving body, the interaction and overlap of technologies can bring issues of the built environment into dance practice and the body into architecture.

\section{An Architecture of Movement}

The geometry of movement is a choreographic tool for contemporary choreographer William Forsythe. His analytic formulations of body and space has led to several collaborations with architecture, of both theoretical and physical kinds - most notably through his friendship with Daniel Libeskind. Through his twenty year directorship of the Frankfurt Ballet and now The Forsythe Company, Forsythe has cultivated an international reputation for innovative and experimental, contemporary ballet. His interest in new ways of notating dance, coupled with a vehemence against static reproductions, has led to novel collaborations in new media and digital design. His work has often been described as 'dance deconstruction', although this term fails to understand Forsythe's process. Rather than deconstructing traditional ballet forms, Forsythe is forging a new process of dance based on the body as a spatial constructor. A key part of this process is the embedding of chance into the choreographic process.

Forsythe has described his process of sculpting lines and geometries in space an architecture of movement, where the line becomes a volume, the body folding and unfolding as it inscribes geometries. Forsythe says, 'Movement is, so to speak, living architecture - living in the sense of changing emplacements as well as changing cohesion. The architecture is created by human movements and is made up of pathways tracing shapes in space [which] we may call "trace-forms"' (qtd. in Spier). This can be clearly understood in Forsythe's contemporary ballet 'Limb's theorem' (1990). Forsythe used Libeskind's 'Endspace' drawings as scores, upon which the dancers extruded three-dimensional, built spaces. The physical dance becomes another iteration or translation of the drawing. The essentially static, planimetric nature of both the architecture and dance drawing is reconsidered as an set of spatial instigators, rather than defined parameters or representations. Libeskind wanted to create a set of drawings that were performative, open to transformation in contrast to the fixed state that conventional architecture drawings had devolved into. The 'Endspace' drawings are an interrogation of the architecture drawing, from which Forsythe choreographed a dance piece that interrogated the formal organizations and movements of ballet.

Forsythe draws his approach to space from the Swiss dance theorist Rudolphe Laban's spatial geometry. Laban described the body's kinosphere as a crystal form. It defines a threedimensional geometry generated from the limits of the outstretched body, which mark twentyseven points in space that tilt and rotate with movement. Based on the real limits of the body, this was defined by Laban as an icosahedron, replacing the Euclidean circle and square described by Vitruvius. Any point in this crystallized form can become the centre of gravity, instead of an original radiating axis. Using Laban's geometry as a spatial framework, Forsythe employs algorithms to create regenerative systems. Forsythe's calls the results 'movement alphabets', based on these internal movement geometries. This alphabet is designed through improvisational processes. It is as if the body were drawing formulas and equations in motion through the air. Dance theorist Gabrielle Brandstetter describes this process as:

The movement of an oscillating "dis- and re-orientation" organizes the structures as a constantly reversible process... the remembering of the order in the movement sequence, the memoria of the passing of time and space -become the generators of a vocabulary that appears like an alternating current... it is an effect that not infrequently awakens in the spectator the impression that a figure or line is growing out of the impulse of both and inward and outward mobilization (46).

This spatial geometry frees Forsythe from the traditional limitations in dance of centering the body in order to produce stability. Instead, the dancer is purposely destabilized and thrown off balance. Potentiality becomes a testing out of the multifarious possibilities of movement in the body. As Brandstetter points out, this architecture of imbalance subverts the assumption of bodily stability (46). He works with disequilibrium and distortion, seemingly contradictory themes for dance, as they are for architecture. Instead of built form, Forsythe is working with the body and space, seeing space as a plastic entity that can be both worked against and acted upon. Destabilization is used to redefine assumptions of centrality and stability, in order to generate movements that are paradoxically more intimately human to watch. To see a dancer on the verge of a fall is far more personally immersive than the incomprehensible control of the typical ballet posture. The results of this process tend toward the freakish, distorted body 
gestures and extreme and sudden shifts in movement, create intense and very powerful dance scores.

In terms of architecture, it is useful to look again at Libeskind's work. Forsythe has described Libeskind's work as a series of decentered spaces (qtd. in Brandstetter 49). The spaces refuse to present the traditional stability that buildings lend to the body, which anchor it in space. This can be experienced in Libeskind's extension to the Jewish Museum in Berlin. Libeskind creates spaces that purposely throw people off balance through extreme floor, walls or ceiling gradients, asymmetric windows and acute angles. The viewer must be constantly on guard, aware of their surroundings. The architecture demands active perception, where bodies must continually realign themselves. The architecture actively works against the body to extract an emotional reaction.

Forsythe understands potentiality in choreography as essentially an opening up of the geometries made by bodies in space. His design process has melded digital programs and physical improvisations, in order to generate new geometries for the moving body. At the core of Forsythe's choreographies is an algorithmic design process, which computer programs can now emulate, generating faster outcomes and documenting that process. But it is the lack of perfection, the glitches and lags and failures and falls of human repetition where Forsythe understands the art lies.

\section{Conclusion}

New developments in the design of contemporary architectures are being led by innovations in technology, whether it is BIM and parametric modelling programs, topological definitions of form and space or prototyping and manufacturing capabilities. This paper follows from a personal interest in what I argue to be the greatest loss risked in these digital acrobatics - the awareness of the animate body in architecture. The changes that are taking place with bodies and spaces, and in the technology of architectural drawing, will continue regardless of how the practice chooses to react. But that in parallel to the development of architectural design techniques and manufacturing, should be recognised the key question of how to incorporate the living body into these new digital and digitised spaces.

This paper has aimed to briefly map out the infiltration of chance and indeterminacy into the design process. By relating in parallel the inter-relations in the dance field and the work of William Forsythe, it proposes new relationships between the animate body, design processes and architecture. The leap into the unknown means allowing these new relationships the opportunity to create new kinds of artworks, whether dance pieces or buildings.

\section{References}

Baudoin, Patricia and Gilpin, Heidi. "Proliferation and Perfect Disorder: William Forsythe and the Architecture of Disappearance." ॥ Disegno che Non Fa il Ritratto: Danza, Architecttura, Notazioni, a cura di Marinella Buatterini, Vol.Il. Teatri di Reggio Emilia,1989.

Brandstetter, Gabriele \& Ulvaeus Marta. "Defigurative Choreography: From Marcel Duchamp to William Forsythe." TDR (1988-) 42 (4) (Winter, 1998): 37-55.

Evans, Robin. "Translations from Drawing to Building and Other Essays." Translations from Drawing to Building and Other Essays. UK: Architecture Association, 1997. 186.

Deleuze, Gilles. The Fold, Leibniz and the Baroque. Trans. by Tom Conley. Minneapolis and London: University of Minnesota Press, 1993.

Massumi, Brian. "Sensing the Virtual, Building the Insensible." Hypersurface Architecture. US: Academy editions, 1998.

Rajchman, John. Constructions. USA: MIT press, 1998.

Spier, Steven. "Dancing and drawing, choreography and architecture." Journal of Architecture 10 (4) (Sept 2005). 